\title{
QUALIDADE DE OVOS DE CODORNAS JAPONESAS: EFEITO DA IDADE DA AVE, TEMPERATURA DE CONSERVAÇÃO E PERÍODO DE ARMAZENAMENTO
}

\author{
Elis Regina de Moraes Garcia ${ }^{1 *}$ \\ Laura Ramos de Ávila \\ Flavia Kleszcz da Cruz ${ }^{3}$ \\ Rosemary Pereira de Pedro Souza ${ }^{2}$ \\ Natália Ramos Batista ${ }^{2}$ \\ William Britez Feliciano ${ }^{2}$ \\ Naiara Nogueira Arguelo ${ }^{2}$
}

GARCIA, E. R. de M.; ÁVILA, L. R. de; CRUZ, F. K. da; SOUZA, R. P. de P.; BATISTA, N. R.; FELICIANO, W. B.; ARGUELO, N. N. Qualidade de ovos de codornas japonesas: efeito da idade da ave, temperatura de conservação e período de armazenamento. Arq. Ciênc. Vet. Zool. UNIPAR, Umuarama, v. 18, n. 4, p. 211-220, out./dez. 2015.

RESUMO: Objetivou-se avaliar a qualidade e a composição de ovos de codornas de diferentes idades armazenados em distintos períodos e ambiente de armazenamento. Foram utilizados 992 ovos, analisados frescos e após armazenamento em temperatura ambiente e refrigerada aos sete, 14 e 21 dias. As variáveis analisadas foram: peso (PO) e perda de peso do ovo (PP), unidade Haugh (UH), índice (IG) e coloração de gema (CG), porcentagens de albúmen (PAL), gema (PG) e casca (PC), sólidos totais do albúmen (SA) e da gema (SG). Para os ovos estocados em temperatura ambiente observou-se interação entre a idade da ave e o tempo de armazenamento para PO, PAL e PG. O tempo de estocagem influenciou de forma quadrática a UH, IG, PP e PC, e linearmente a CG e SA. A idade da ave influenciou a UH. Ovos sob refrigeração apresentaram interação entre a idade da ave e o período de armazenamento para PG. O avanço do tempo de conservação influenciou de forma quadrática o PO e CG, e linearmente a UH, IG, PP, PG, PC e SG. A idade da ave influenciou o PO, IG (P $<0,05)$, a PP, PAL $(\mathrm{P}<0,01)$ e SA $(\mathrm{P}<0,05)$. Os ovos produzidos por codornas mais velhas são mais susceptíveis a perda de qualidade interna. Quando armazenados sob temperatura ambiente os ovos de codornas apresentam perdas acentuadas de qualidade interna durante a estocagem por até 21 dias, independente da idade das aves. A refrigeração apresenta-se como uma alternativa para prolongar a qualidade interna dos ovos de codornas.

PALAVRAS-CHAVE: Composição química. Período de estocagem. Porcentagem de gema. Refrigeração. Unidade Haugh.

\section{QUALITY OF JAPANESE QUAIL EGGS: EFFECT OF AGE OF BIRD, TEMPERATURE STORAGE AND PERIOD OF STORAGE}

\begin{abstract}
This study aimed to evaluate the quality and composition of quail eggs of different ages stored in different periods and storage environment. It was used $992 \mathrm{eggs}$, fresh analyzed and after storage at ambient temperature and refrigerated at seven, fourteen and twenty-one days. The variables analyzed were: weight (PO) and weight loss egg (PP), Haugh unit (HU), index (IG) and yolk color (CG), percentages of albumen (PAL), gem (PG), bark (PC), total solids of the albumen (SA) and yolk (SG). For eggs stored at ambient temperature it was observed interaction between the age of the bird and the storage time for PO, PG and PAL. The storage time had a quadratic effect on HU, IG, PP and PC, and linearly CG and SA. The age of the bird influenced the UH. Eggs under refrigeration showed interaction between the age of the bird and the storage period for PG. The advancement of storage time had a quadratic effect the PO and CG, and linearly at UH, IG, PP, PG, PC and SG. The age of the bird influenced the PO, IG $(\mathrm{P}<0,05)$, the PP, PAL $(\mathrm{P}<0,01)$ and $\mathrm{SA}(\mathrm{P}<0,05)$. The eggs produced by older quail are more susceptible to loss of internal quality. When stored at ambient temperature eggs quail exhibit marked loss of internal quality during storage for up to 21 days, regardless of the age of the birds. The cooling is presented as an alternative to improve the internal quality of the eggs of quail
\end{abstract}

KEYWORDS: Chemical composition. Cooling. Haugh unit. Percentage of yolk. Storage time.

\section{CALIDAD DE HUEVOS DE CODORNICES JAPONESAS: EFECTO DE LA EDAD DEL AVE, TEMPERATURA DE CONSERVACIÓN Y PERÍODO DE ALMACENAMIENTO}

RESUMEN: Se ha buscado evaluar la calidad y la composición de huevos de codornices de diferentes edades, almacenados en distintos períodos y ambientes. Se han utilizado y analizado 992 huevos frescos y después almacenados en temperatura ambiente y refrigerada a los 7, 14 y 21 días. Las variables analizadas fueron: peso (PO) y pérdida de peso del huevo (PP), unidad Haugh (UH), índice (IG) y coloración de la yema (CG), porcentajes de albumen (PAL), yema (PG) y cáscara (PC), sólidos totales del albumen (SA) y de la yema (SG). Para los huevos estocados en temperatura ambiente se ha observado in-

DOI: https://doi.org/10.25110/arqvet.v18i4.2015.5746

${ }^{1}$ Professora do Curso de Zootecnia e do Programa de Pós-graduação em Zootecnia - Universidade Estadual de Mato Grosso do Sul - Rodovia Aquidauana/ UEMS - Km 12 - CEP: 79200-000 - Aquidauana, MS. Brasil. E-mail: ermgarcia@uems.br. *Autor para correspondência.

${ }^{2}$ Universidade Estadual de Mato Grosso do Sul, Aquidauana, MS.

${ }^{3}$ Universidade Estadual de Maringá, Maringá, PR. 
teracción entre la edad del ave y el tiempo de almacenamiento para PO, PAL y PG. El tiempo de almacenaje influjo de forma cuadrática a UH, IG, PP y PC, y linealmente a CG y SA. La edad del ave y el periodo influjo a UH. Huevos bajo refrigeración presentaron interacción entre la edad del ave y el período de almacenamiento para PG. El avance del tiempo de conservación influjo de forma cuadrática el PO y CG, y linealmente a UH, IG, PP, PG, PC y SG. La edad del ave influjo el PO, IG (P<0,05), el PP, PAL $(\mathrm{P}<0,01)$ y SA $(\mathrm{P}<0,05)$. Los huevos producidos por codornices mayores son más susceptibles a la pérdida de calidad interna. Cuando almacenados bajo temperatura ambiente por 21 días, los huevos de codornices presentan pérdidas acentuadas de calidad interna, independiente de la edad de las aves. La refrigeración se presenta como una alternativa para prolongar la calidad interna de los huevos.

PALABRAS CLAVE: Composición química. Periodo de almacenaje. Porcentaje de yema. Refrigeración. Unidad Haugh.

\section{Introdução}

A coturnicultura tem apresentado um desenvolvimento acentuado nos últimos anos, isso graças às novas tecnologias de produção. A atividade antes de subsistência passou a ocupar um panorama de atividade altamente tecnificada, com resultados promissores aos investidores (PASTORE; OLIVEIRA; MUNIZ, 2012). No Brasil, a produção de ovos de codornas é realizada com o uso de linhagens de alta produtividade, garantindo oferta suficiente do produto no mercado (FUJIKURA, 2002).

A composição de ovos de codorna consiste de aproximadamente $73,78 \%$ de água, a gema é constituída de 30\% de gordura e $19 \%$ de proteína. O albúmen é constituído de aproximadamente $11 \%$ de proteína, já a quantidade de vitaminas é de 300 UI e minerais $1,13 \%$ no ovo inteiro (MORAES; ARIKI, 2000).

É importante salientar que a qualidade do ovo atinge o seu máximo no momento da postura. Após esse momento, para a manutenção da qualidade, devem-se levar em consideração os fatores que podem influenciar a qualidade, como o tempo de armazenamento, temperatura, umidade e manipulação (SOUZA et al., 1998).

Muitos atributos de qualidade do albúmen e gema são perdidos ao longo do período de armazenamento do ovo. A velocidade em que essas alterações ocorrem no albúmen e na gema está ligada à temperatura e à perda de $\mathrm{CO}_{2}$ do albúmen por meio da casca (OLIVEIRA, 2006).

A idade da poedeira é outro fator que exerce influência direta sobre a qualidade, composição e tamanho do ovo, visto que com o avanço da idade da ave ocorre à redução na taxa de postura e alterações nos constituintes do ovo, principalmente gema e albúmen (ROCHA et al., 2008).

Desse modo, o presente trabalho foi desenvolvido com o objetivo de avaliar a qualidade de ovos de codornas de diferentes idades armazenados em distintos períodos e ambiente de armazenamento.

\section{Material e Métodos}

O experimento foi desenvolvido no Laboratório de Qualidade de Produtos de Origem Animal da Universidade Estadual de Mato Grosso do Sul (UEMS) - Unidade Universitária de Aquidauana. Foram utilizados 992 ovos de codornas japonesas com 13 e 40 semanas de idade divididos em dois experimentos conforme a metodologia a seguir:

\section{Experimento I}

Os ovos foram coletados na granja Keiko Kuraka- wa, no período da tarde, logo após a postura, transportados para UEMS, e armazenados sob temperatura ambiente $( \pm$ $24,25{ }^{\circ} \mathrm{C}$ ) em estojos plásticos devidamente identificados. As análises foram realizadas no dia da coleta (ovos frescos), aos sete, 14 e 21 dias de armazenamento.

Adotou-se um delineamento inteiramente casualizado, em esquema fatorial 2 x 4 (idade da codorna x período de armazenamento).

Para avaliação da qualidade interna foram analisados 30 ovos para cada idade e período de armazenamento, sendo que os dados obtidos para cada ovo foram considerados uma observação. As variáveis analisadas foram: peso (PO) e perda de peso do ovo (PP), unidade Haugh (UH), índice (IG) e coloração de gema (CG).

Todos os ovos foram pesados em balança semi-analítica $( \pm 0,001 \mathrm{~g})$ no dia da coleta e no dia das análises de acordo com o período de armazenamento, obtendo a diferença da PP. Posteriormente, os ovos foram quebrados em uma superfície plana e lisa de vidro, e com o auxílio de um paquímetro digital foi aferido a altura do albúmen denso e da gema, (mm). Foram determinados os valores de UH, utilizando a seguinte equação (NESHEIM; AUSTIC; CARD, 1979): $\mathrm{UH}=100 \times \log (\mathrm{H}-1,7 \mathrm{P} 0,37+7,57)$, em que, $\mathrm{H}=$ altura do albúmen $(\mathrm{mm}) ; \mathrm{P}=$ peso do ovo $(\mathrm{g})$.

Em seguida, utilizando um paquímetro manual $( \pm$ $0,01 \mathrm{~mm}$ ) foi determinado o diâmetro da gema e com base nos valores obtidos foi calculado o IG (altura/diâmetro). A CG foi analisado por meio do leque colorimétrico DSM (Yolk Color Fan)®.

Para análise da composição foram analisados 40 ovos, considerando cada idade e período de estocagem sendo que os dados obtidos para cada ovo foram considerados uma observação. As variáveis avaliadas foram: as porcentagens de albúmen (PAL), gema (PG) e casca (PC) dos ovos.

Para a determinação das PAL, PG e PC, os ovos foram pesados, quebrados, e o albúmen e a gema separados por meio de um separador de gemas, colocados individualmente em copos plásticos para a pesagem. As cascas foram lavadas, retirando-se apenas o resíduo de albúmen, e secas em temperatura ambiente por 48 horas. Após a secagem, as amostras das cascas foram pesadas. A partir dos valores obtidos calcularam-se as PAL, PG e PC.

Para análises de sólidos totais, o conteúdo interno dos mesmos ovos utilizados para a obtenção das porcentagens foram homogeneizados em 4 "pools" de 10 ovos, pesados e colocados em recipientes de alumínio, devidamente identificados. Essas amostras permaneceram por 72 horas em estufa de ventilação forçada $\left(55^{\circ} \mathrm{C}\right)$ e, após secagem foi efetuada a pesagem dos mesmos. 


\section{Experimento II}

A metodologia utilizada no experimento II foi a mesma empregada no experimento I, no entanto, os ovos utilizados foram armazenados em ambiente refrigerado $( \pm 4,95$ $\left.{ }^{\circ} \mathrm{C}\right)$.

\section{Análise estatística}

Dentro de cada ambiente de conservação, os dados referentes aos efeitos da idade da ave e período de estocagem foram submetidos à análise de variância $(\mathrm{P}<0,05)$. Quando influenciados pelo fator tempo de armazenamento os graus de liberdade foram desdobrados em polinômios ortogonais $(\mathrm{P}<0,05)$.

\section{Resultados e Discussão}

\section{Experimento I}

Os dados referentes à qualidade de ovos de codornas de diferentes idades e armazenados sob temperatura ambiente são apresentados na Tabela 1. Observou-se interação entre a idade da ave e o período de armazenamento para o $\mathrm{PO}$, de forma que os ovos produzidos por aves mais velhas (40 semanas) apresentaram maior peso quando comparados àqueles provenientes de codornas com 13 semanas de idade. No entanto, ao longo do período de armazenamento houve redução linear do PO para ambas as idades, com perdas mais acentuadas em ovos de codornas mais jovens (Figura 1).

Tabela 1: Peso do ovo (PO), porcentagem de perda de peso (PP), unidade Haugh (UH), índice de gema (IG) e coloração de gema crua (CG), de ovos de codornas japonesas com diferentes idades (ID) e período de armazenamento (PA) sob temperatura ambiente por 21 dias

\begin{tabular}{cccccc}
\hline ID (semanas)* & PO $(\mathrm{g})$ & $\mathrm{PP}(\%)$ & $\mathrm{UH}$ & $\mathrm{IG}(\mathrm{mm})$ & $\mathrm{CG}$ \\
\hline 13 & 10,49 & 2,83 & $81,32 \mathrm{a}$ & $0,305 \mathrm{a}$ & 4,31 \\
40 & 10,90 & 2,88 & $78,91 \mathrm{~b}$ & $0,285 \mathrm{~b}$ & 4,30 \\
\hline PA (dias)** & \multicolumn{7}{c}{0} \\
\hline 0 & 11,04 & 0,00 & 91,89 & 0,466 & 4,52 \\
7 & 10,91 & 2,34 & 81,14 & 0,292 & 4,37 \\
14 & 10,58 & 3,66 & 77,88 & 0,255 & 4,32 \\
21 & 10,24 & 5,43 & 70,54 & 0,166 & 4,02 \\
\hline \multicolumn{7}{c}{ Valores de P } \\
ID & $<0,01$ & $>0,05$ & $<0,01$ & $>0,05$ \\
PA & $<0,01$ & $<0,01$ & $<0,01$ & $<0,01$ & $<0,01$ \\
ID x PA & 0,036 & $>0,05$ & $>0,05$ & $>0,05$ & 0,263
\end{tabular}

* Na coluna, médias seguidas de letras diferentes diferem entre si pelo $\mathrm{F}(\mathrm{P}<0,05)$.

Figura 1: Desdobramento da interação entre idade da ave e período de armazenamento (21 dias) para o peso dos ovos armazenados sob temperatura ambiente

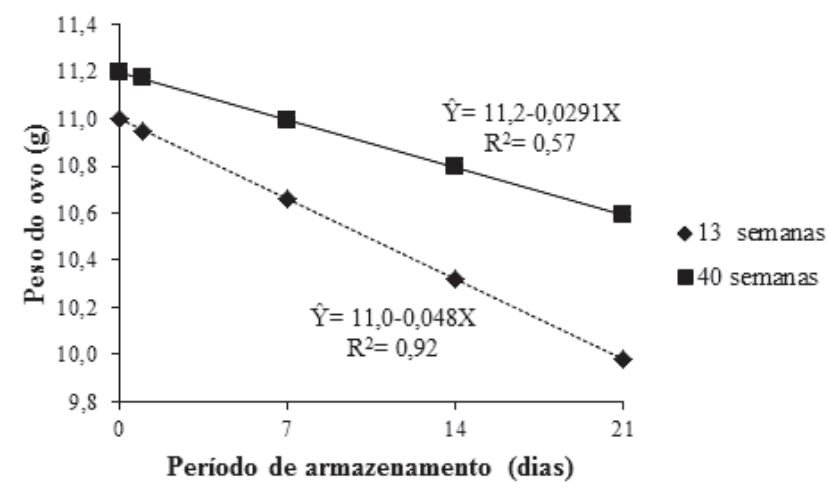

A redução de água do albúmen, perdida por meio dos poros da casca durante o processo de trocas gasosas (saída de umidade e dióxido de carbono) que ocorre continuamente após a postura é uma das principais causas da PP, podendo ser acelerada por condições inadequadas de armazenamento, principalmente quando associadas às altas temperaturas (JONES et al., 2002). Esse resultado foi constatado por Freitas et al. (2011), ao armazenarem ovos de poedeiras comerciais em temperatura ambiente por 21 dias.
Com o avanço do período de armazenamento, a PP (\%) dos ovos aumentaram linearmente (Figura 2). Estudando o efeito do armazenamento em ovos de codornas com 35 semanas de idade, Seibel et al. (2005) concluíram que a PP foi maior quando os ovos foram armazenados em alta temperatura $\left(26,2{ }^{\circ} \mathrm{C}\right)$, perdendo mais umidade para o meio.

Figura 2: Perda de peso (\%) de ovos provenientes de codornas japonesas armazenados por 21 dias sob temperatura ambiente

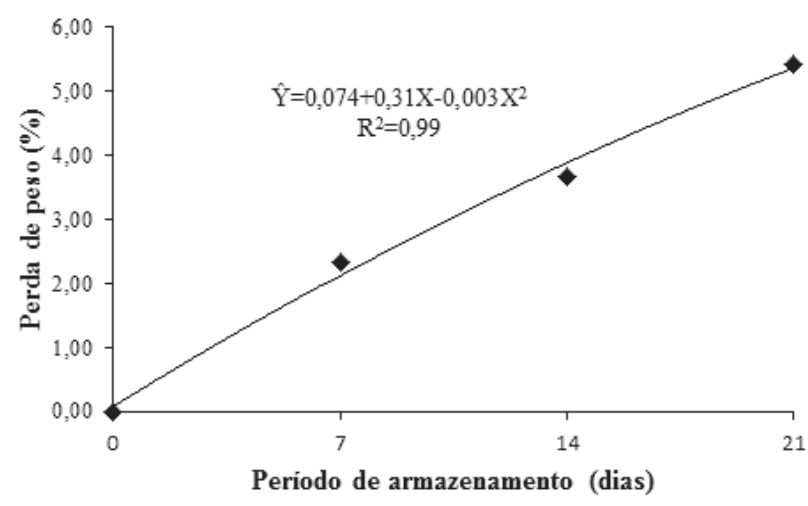

As variáveis UH e IG ( $\mathrm{mm})$ foram influenciadas significativamente pela idade das aves, de forma que os 
maiores valores foram observados nos ovos provenientes de poedeiras jovens (Tabela 1). A UH também foi negativamente influenciada pelo período de estocagem (Figura 3) apresentando efeito quadrático decrescente com o avanço do período de armazenamento (ponto de mínimo: 24,83 dias).

Figura 3: Valores de unidade Haugh de ovos provenientes de codornas japonesas armazenados por 21 dias sob temperatura ambiente

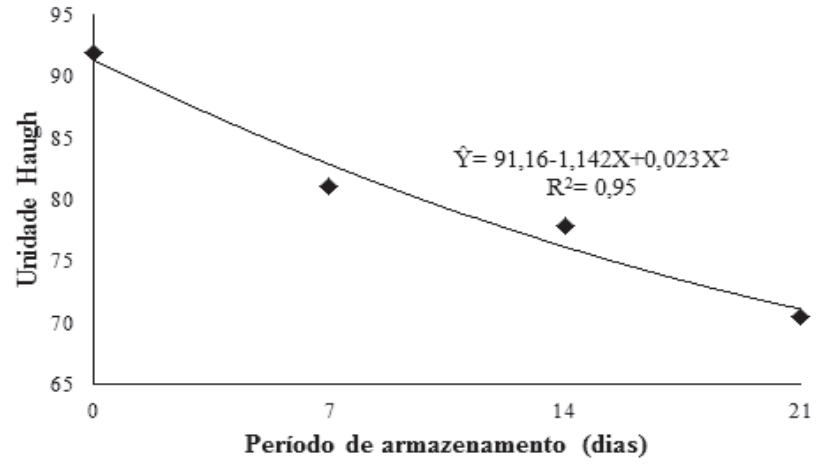

Durante a estocagem dos ovos ocorre elevação do $\mathrm{pH}$ do albúmen de 6,5 para 9,5 devido, provavelmente, as perdas de $\mathrm{CO}_{2}$ por meio dos poros da casca que causam a hidrólise das cadeias de aminoácidos, as quais liberam a água que estava ligada a grandes moléculas de proteínas principalmente da ovomucina, implicando na fluidificação e redução da viscosidade do albúmen mais denso, influenciando diretamente na redução dos valores da UH (SGARBIERI, 1996).

Este evento poderia explicar o comportamento quadrático decrescente observado para IG, quando os ovos foram mantidos em temperatura ambiente ao longo do período de armazenamento (Figura 4), com ponto de mínimo em 28,75 dias.

Naturalmente, por meio da pressão osmótica, o albúmen fluido atravessa a membrana vitelínica e fica retido na gema (MORENG; AVENS, 1990). Com a liberação de água e seu excesso no albúmen resultante das reações bioquímicas ocorridas durante a estocagem, ocorre aumento da permeabilidade e enfraquecimento da membrana vitelínica, facilitando a transferência do excedente da água para a gema, tornando-a flácida e achatada, além de fácil rompimento durante a manipulação do ovo (MARINHO, 2011).

Figura 4: Índice de gema de ovos provenientes de codornas japonesas armazenados por 21 dias sob temperatura ambiente

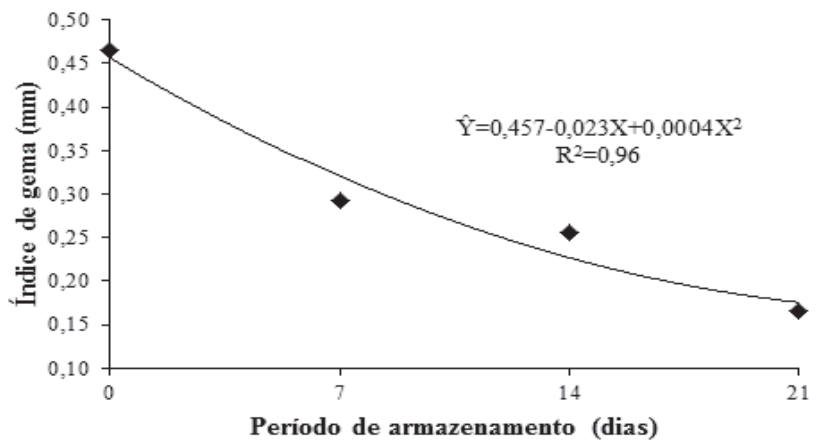

Não houve efeito da idade das aves para a CG, no entanto, ao longo do período de armazenamento esta reduziu linearmente $(\mathrm{P}<0,01)$ quando os ovos foram estocados sob temperatura ambiente (Figura 5).

O mesmo resultado foi observado por Ferreira (2013), ao avaliar a qualidade de ovos de poedeiras de diferentes idades ( 28 e 80 semanas), armazenados sob temperatura ambiente. Resultados semelhantes também foram encontrados por Santos et al. (2009), ao armazenarem ovos de galinhas poedeiras durante sete, 14 e 21 dias em temperatura ambiente, acentuando-se a queda da coloração a partir dos 14 dias de armazenamento.

Figura 5: Coloração de gema crua de ovos provenientes de codornas japonesas armazenados por 21 dias sob temperatura ambiente

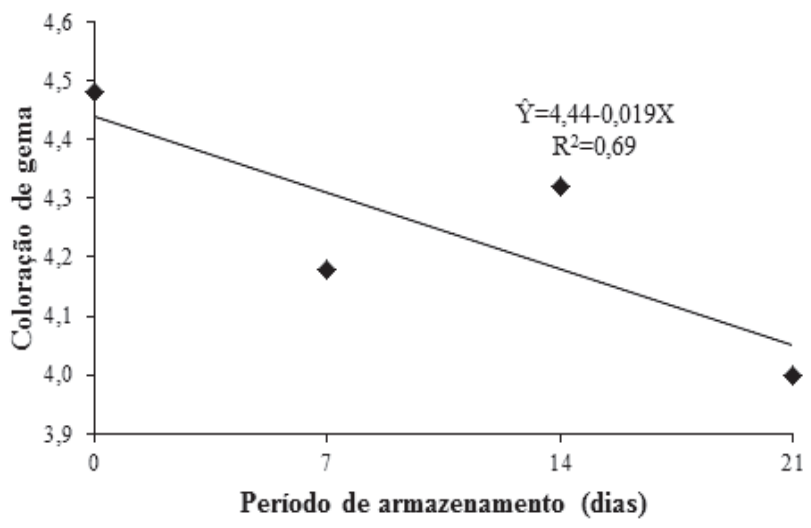

Os valores referentes à composição de ovos provenientes de codornas japonesas com diferentes idades e armazenados sob temperatura ambiente por 21 dias encontram-se na Tabela 2. Houve interação entre a idade da poedeira e o período de armazenamento para PG (Figura 6), de forma que os ovos de codornas mais velhas apresentaram aumento quadrático (ponto máximo 13,25), enquanto que os ovos das aves mais jovens demonstraram redução quadrática (com ponto mínimo 6,95 ) com avanço do período de estocagem.

Em concordância com os resultados obtidos neste trabalho, Sousa (2013) relatou que ovos de poedeiras de inicio e final de produção apresentaram menores e maiores porcentagem de gema respectivamente, quando estes foram estocados por 20 dias sob temperatura ambiente.

O período de armazenamento reduziu linearmente a PAL dos ovos armazenados em temperatura ambiente (Figura 7). Estes resultados confirmam os resultados encontrados para a UH, uma vez que as intensas alterações bioquímicas ocorridas durante o armazenamento resultam na liquefação do albúmen denso liberando água, diminuindo assim a quantidade de albúmen no interior do ovo, influenciando diretamente sobre essas variáveis.

Scatoline-Silva et al. (2013) relataram que a perda de $\mathrm{CO}_{2}$ por meio da casca é uma das principais causas da deterioração do albúmen e a degradação das proteínas no albúmen denso.

Em estudos com ovos estocados por 21 dias em temperatura ambiente, Santos et al. (2009) destacaram que a PAL reduziu ao longo do período de armazenamento, pois o albúmen muda sua consistência e há perda de umidade em períodos prolongados de estocagem. 
Tabela 2: Porcentagens de albúmen (PAL), gema (PG) e casca (PC), sólidos totais do albúmen (SA) e gema (SG) de ovos de codornas japonesas armazenados sob temperatura ambiente em função da idade (ID) e do período de armazenamento (PA)

\begin{tabular}{|c|c|c|c|c|c|}
\hline \multirow[t]{2}{*}{ ID (semanas)* } & \multicolumn{3}{|c|}{ Porcentagens } & \multicolumn{2}{|c|}{ Sólidos totais (\%) } \\
\hline & PAL & PG & $\mathrm{PC}$ & SA & SG \\
\hline 13 & 50,36 & 34,19 & 15,45 & 8,60 & 17,20 \\
\hline 40 & 50,87 & 35,19 & 14,91 & 8,20 & 17,76 \\
\hline \multicolumn{6}{|l|}{ PA (dias) } \\
\hline 0 & 54,98 & 31,40 & 13,62 & 8,99 & 18,85 \\
\hline 7 & 51,03 & 34,39 & 14,58 & 8,26 & 17,07 \\
\hline 14 & 50,02 & 35,40 & 14,57 & 8,52 & 18,26 \\
\hline 21 & 46,77 & 38,23 & 17,60 & 7,84 & 15,72 \\
\hline \multicolumn{6}{|c|}{ Valores de $\mathrm{P}$} \\
\hline ID & 0,292 & 0,021 & 0,185 & 0,104 & $>0,05$ \\
\hline PA & $<0,01$ & $<0,01$ & $<0,01$ & $<0,01$ & 0,791 \\
\hline ID $x$ PA & $>0,05$ & $<0,01$ & 0,391 & 0,241 & $>0,05$ \\
\hline
\end{tabular}

*Na coluna, médias seguidas de letras diferentes diferem entre si pelo $\mathrm{F}(\mathrm{P}<0,05)$.

Figura 6: Desdobramento da interação entre a idade da ave e período de armazenamento (21 dias), para porcentagem de gema armazenada sob temperatura ambiente

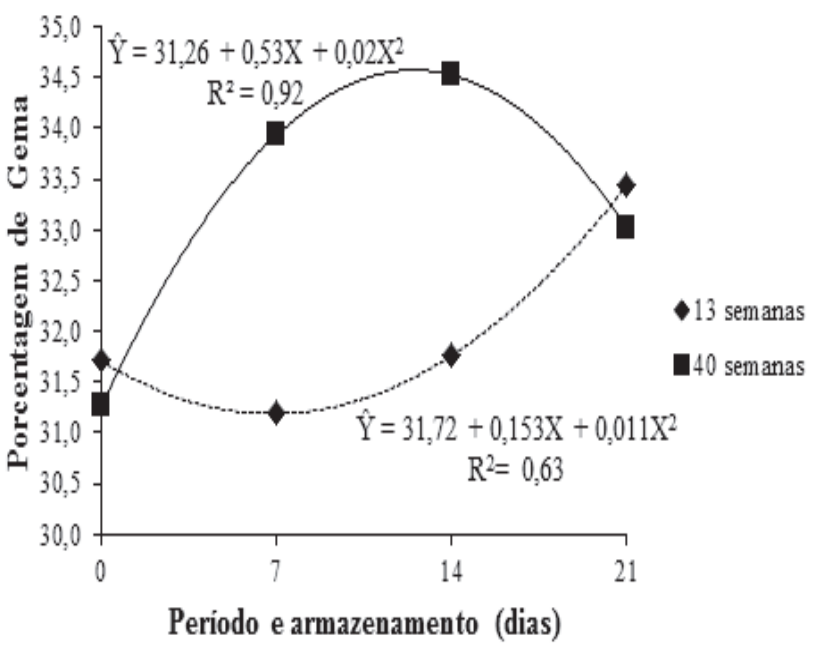

Figura 7: Porcentagem de albúmen de ovos provenientes de codornas japonesas, armazenados por 21 dias sob temperatura ambiente

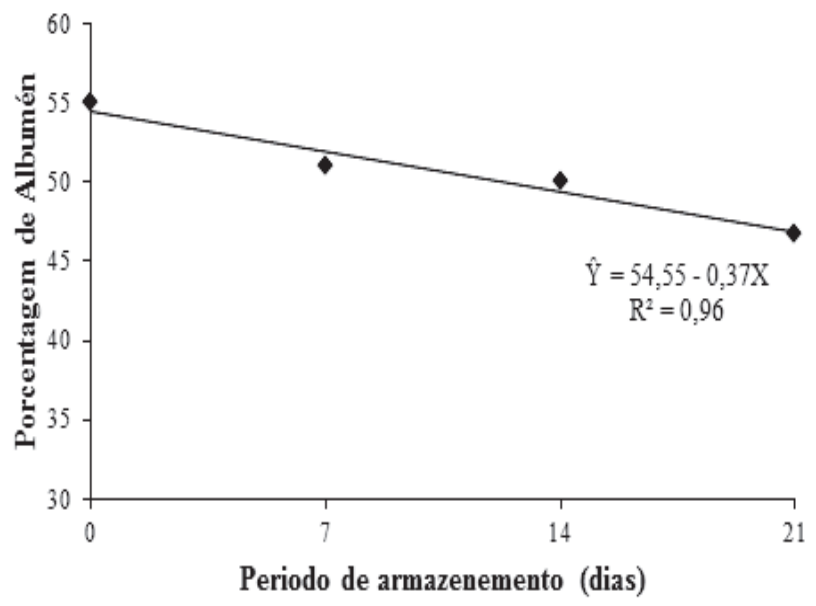

período de armazenamento quando armazenados sob temperatura ambiente (Figura 8) evidenciando que, provavelmente, mudanças no percentual de albúmen proporcionaram aumento na PC. Santos et al. (2009) ressaltaram que ovos estocados em temperatura ambiente apresentaram maior PC, devido as maiores perdas de umidade do ovo.

Figura 8: Porcentagem de casca de ovos provenientes de codornas japonesas, armazenados por 21 dias sob temperatura ambiente

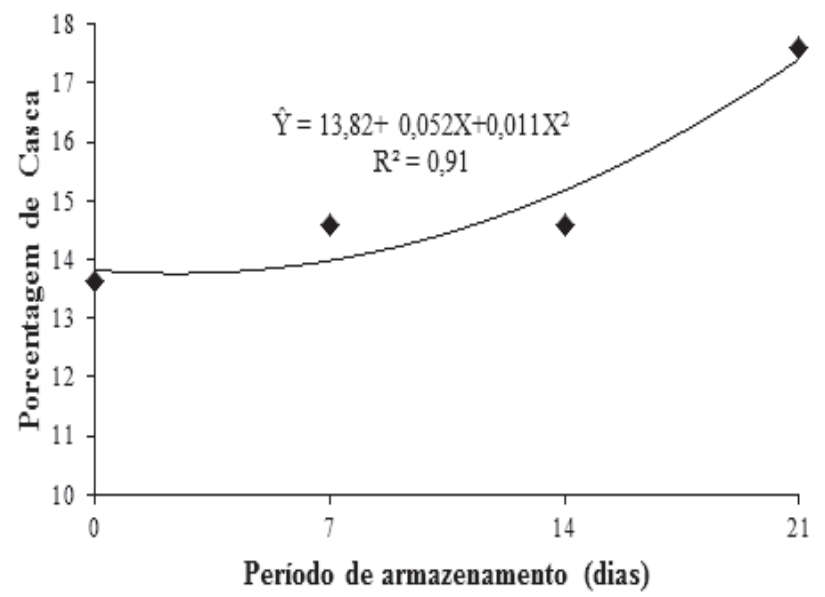

Os valores referentes aos SA apresentaram efeito quadrático decrescente com o avanço do período de armazenamento (Figura 9). Esses resultados diferiram dos verificados por Garcia et al. (2010) que, ao avaliarem ovos provenientes de poedeiras com 55 semanas, constataram que a porcentagem de SA aumentou linearmente com o avanço do período de estocagem.

A PC dos ovos apresentou efeito quadrático para o 
Figura 9: Sólidos totais (\%) do albúmen de ovos provenientes de codornas japonesas armazenados por 21 dias sob temperatura ambiente

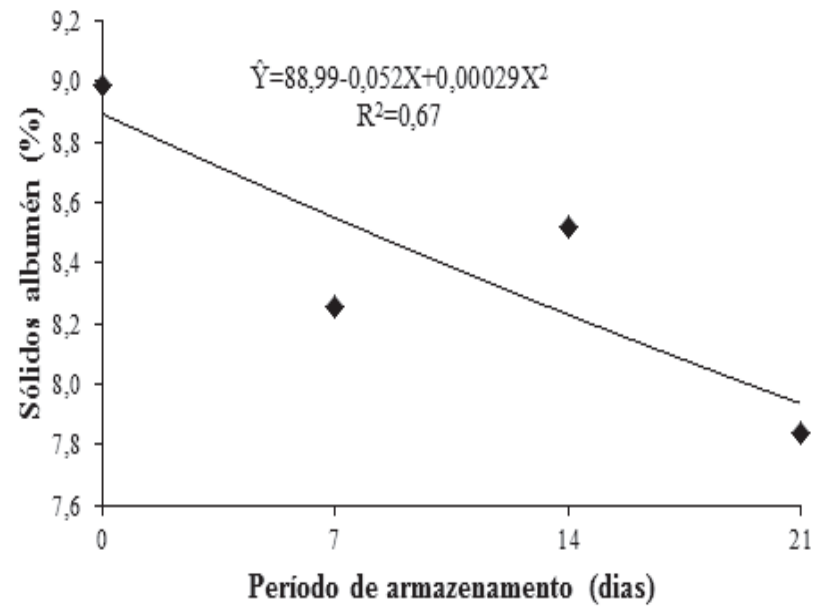

A porcentagem de SG dos ovos reduziu linearmente com o avanço do período de armazenamento em temperatura ambiente (Figura 10). Este resultado, possivelmente, pode ser explicado pela transferência da água do albúmen para a gema, diminuindo o seu percentual de sólidos totais.

Resultados semelhantes foram encontrados por Figueiredo (2012) que descreveu que o conteúdo de SG pode ser afetado pela mobilização de água do albúmen, no entanto a idade, dieta, proteínas e lipídios da gema podem apresentar efeitos que não estão totalmente esclarecidos.
Figura 10: Sólidos totais (\%) da gema de ovos provenientes de codornas japonesas armazenados por 21 dias sob temperatura ambiente

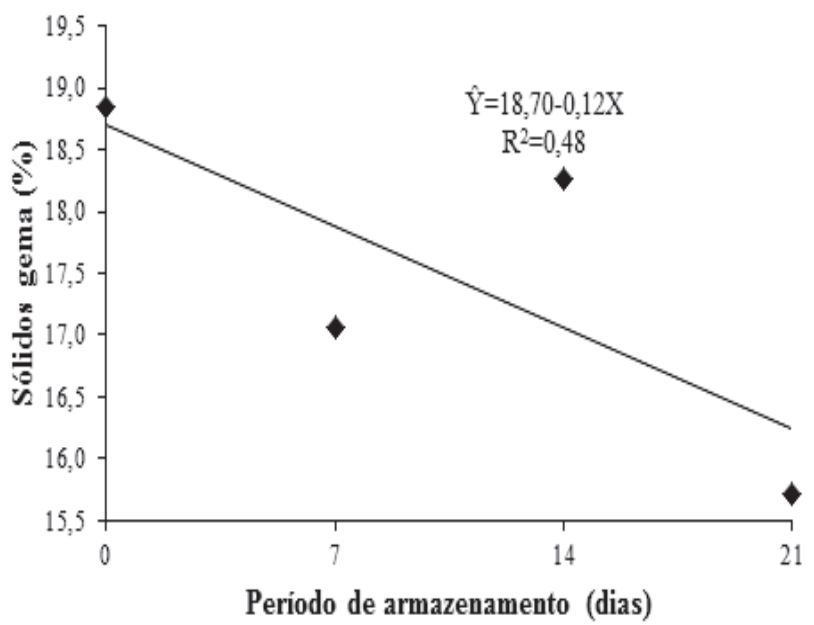

\section{Experimento II}

Os dados referentes à qualidade de ovos de codornas de diferentes idades e armazenados sob temperatura refrigerada são apresentados na Tabela 3. Os ovos de codornas de 40 semanas de idade apresentaram maior peso em comparação às aves mais jovens, fato explicado pelas aves mais velhas apresentarem intervalo entre ovulação maior, fazendo com o ovo permaneça por mais tempo no oviduto da ave, possibilitando maior deposição de nutrientes na gema e no albúmen.

Tabela 3: Peso do ovo (PO), porcentagem de perda de peso (PP), unidade Haugh (UH), índice de gema (IG) e coloração de gema crua (CG), de ovos de codornas japonesas com diferentes idades (ID) e período de armazenamento (PA) sob temperatura refrigerada por 21 dias

\begin{tabular}{cccccc}
\hline ID (semanas)* & PO $(\mathrm{g})$ & PP $(\%)$ & UH & IG $(\mathrm{mm})$ & CG \\
\hline 13 & $10,72 \mathrm{~b}$ & $1,05 \mathrm{~b}$ & 88,61 & $0,459^{\mathrm{a}}$ & 4,31 \\
40 & $10,97 \mathrm{a}$ & $1,20 \mathrm{a}$ & 88,01 & $0,449^{\mathrm{b}}$ & 4,30 \\
\hline PA (dias) & \multicolumn{5}{c}{} \\
\hline 0 & 10,83 & 0,00 & 93,19 & 0,464 & 4,52 \\
7 & 10,84 & 0,83 & 90,14 & 0,463 & 4,37 \\
14 & 11,17 & 1,47 & 86,24 & 0,444 & 4,32 \\
21 & 10,53 & 2,21 & 0,446 & 4,02 \\
\hline \multicolumn{7}{c}{ Valores de P } \\
ID & 0,047 & $<0,01$ & 0,310 & 0,058 & $>0,05$ \\
PA & $<0,01$ & $<0,01$ & $>0,01$ & $<0,01$ & $<0,01$ \\
ID x PA & $>0,05$ & 0,092 & 0,149 & $>0,05$ & 0,263 \\
\hline
\end{tabular}

*Na coluna, médias seguidas de letras diferentes diferem entre si pelo $\mathrm{F}(\mathrm{P}<0,05)$.

Por outro lado, houve efeito quadrático do PO em função do período de armazenamento, independente da idade das aves, com ponto de máximo aos 9,25 dias (Figura 11). Isso possivelmente pode ser explicado pelo fato que durante o experimento não houve classificação de tamanho de ovo, portanto, ovos maiores foram avaliados juntamente com ovos menores. 
Figura 11: Peso do ovo (g) proveniente de codornas japonesas armazenados por 21 dias sob ambiente refrigerado

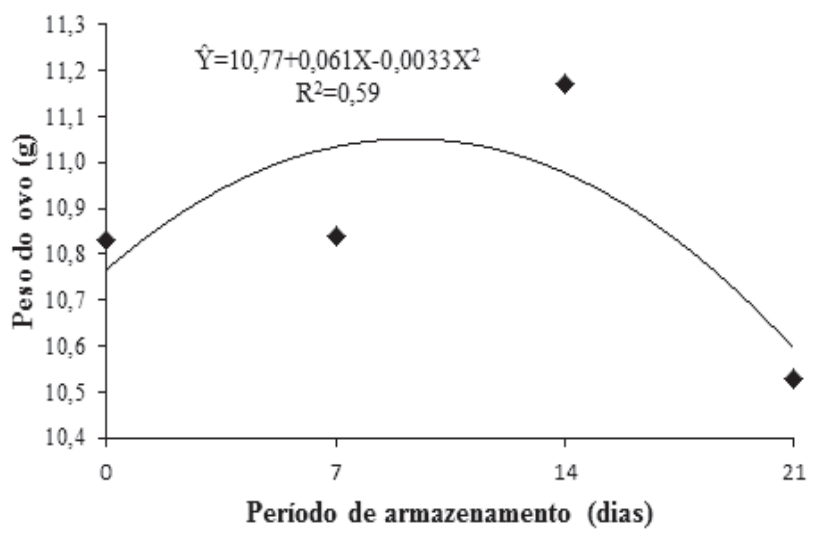

Os ovos de codornas possuem a membrana interna da casca ainda mais espessa quando comparados a ovos de galinha, e mesmo sendo praticamente metade da espessura de um ovo de galinha, a membrana dos ovos de codornas é responsável por manter a qualidade interna por maior tempo devido à reduzida troca gasosa e, consequentemente, menor perda de umidade, podendo ser otimizada pela conservação em ambiente refrigerado (MARINHO, 2011).

A PP dos ovos apresentou aumento linear durante o armazenamento (Figura 12), demonstrando que aves jovens (13 semanas) apresentaram menor susceptibilidade à perda de peso quando comparados aos ovos produzidos por codornas mais velhas (40 semanas), ao longo de 21 dias de armazenamento. Essa perda, possivelmente, foi mais acentuada em ovos de codornas mais velhas, pelo fato que aves velhas produzem ovos com má qualidade de casca.

Ao avaliarem a perda da qualidade interna de ovos de galinhas poedeiras em função do período de armazenamento ( 0 a 35 dias) e ambiente de conservação (ambiente e refrigerado), Barbosa et al. (2008) verificaram resultados semelhantes aos deste estudo, com perda linear no peso dos ovos quando mantidos em ambiente refrigerado a medida que aumentavam o período de estocagem. Os autores relataram que ao longo do armazenamento, as perdas de peso dos ovos sob refrigeração são menos acentuadas quando comparadas à temperatura ambiente, bem como constatado por Oliveira (2006) e Freitas et al. (2011).

Figura 12: Perda de peso $(\%)$ de ovos proveniente de codornas japonesas armazenados por 21 dias sob temperatura refrigerada

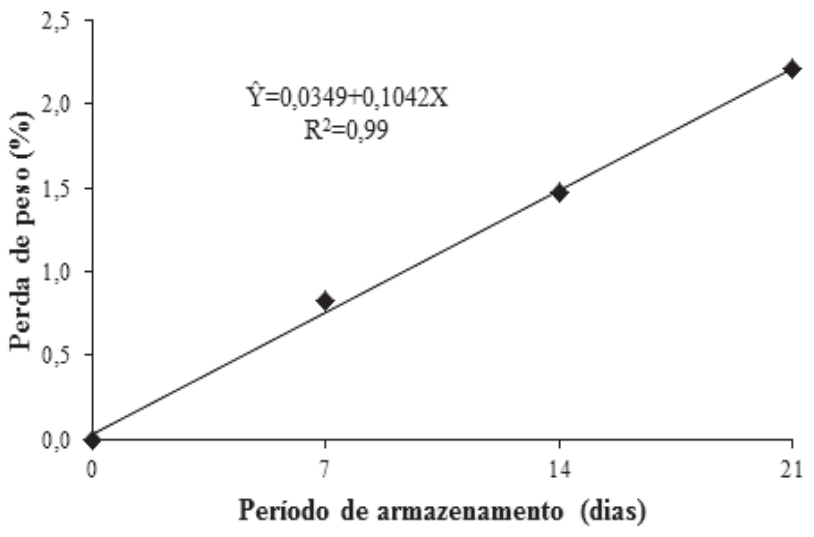

Os valores de UH, IG e CG dos ovos não foram influenciados pela idade da codorna. No entanto, os valores de UH (Figura 13) e IG (Figura 14) reduziram linearmente com o avanço do período de estocagem. Resultados contraditórios foram encontrados por Moura et al. (2008), os quais não observaram redução da altura de albúmen e da UH em ovos de codornas, relatando que a refrigeração atenuou o efeito deletério durante a estocagem dos ovos.

Figura 13: Valores de unidade Haugh de ovos provenientes de codornas japonesas armazenados por 21 dias sob temperatura refrigerada

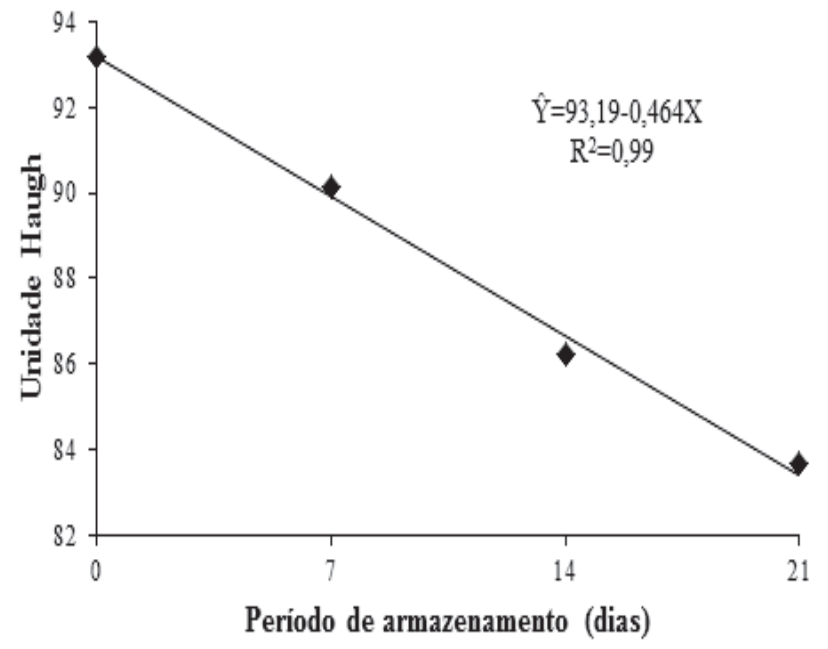

Figura 14: Índice de gema de ovos provenientes de codornas japonesas armazenados por 21 dias sob temperatura refrigerado

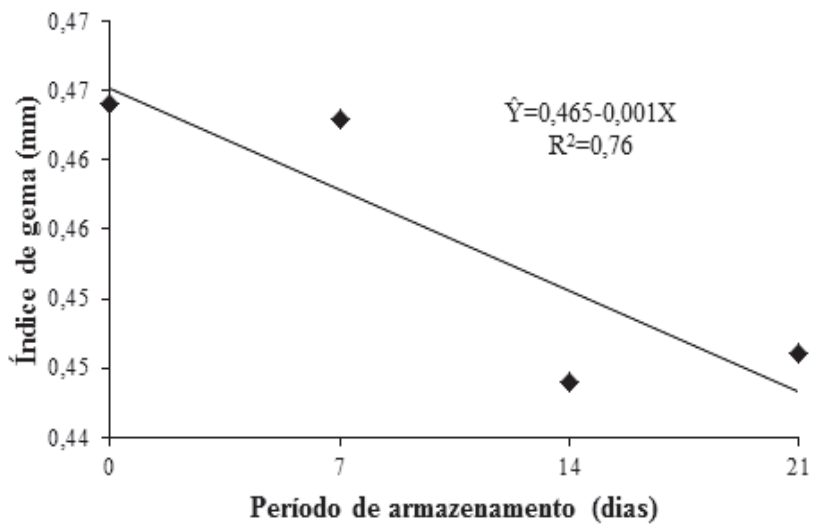

Por outro lado, esses resultados corroboram os encontrados por Barbosa et al. (2008) que, ao armazenarem ovos durante seis períodos de estocagem (zero, sete, 14, 21, 28 e 35 dias) em duas temperaturas (ambiente e refrigeração), também verificaram queda da qualidade interna com o decorrer dos dias, porém, esse efeito foi agravado quando os ovos permaneceram em ambiente sem refrigeração.

Com o avanço do período de armazenamento, os ovos apresentaram efeito quadrático para CG (Figura 15), com redução da coloração a partir dos sete dias de estocagem.

Ao estocarem ovos sob temperatura refrigerada, Andrade et al. (2009) relataram que a CG pode ser influenciada pelo tempo de armazenamento. Santos et al. (2009) e Vidal 
(2009) relataram que a CG podem sofrer alterações durante o armazenamento devido a transferência de ferro da gema para o albúmen, conferindo coloração rósea ao albúmen.

Figura 15: Coloração de gema crua de ovos proveniente de codornas japonesas armazenados por 21 dias sob temperatura refrigerada

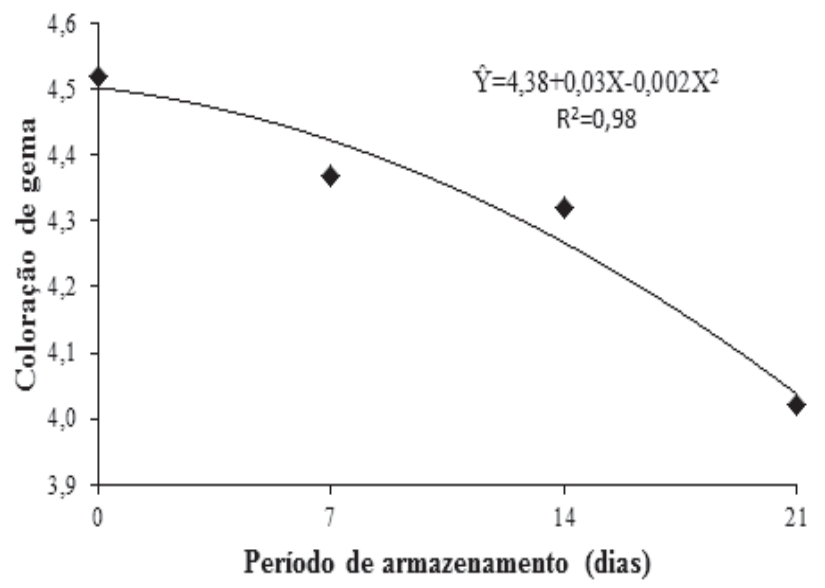

Os valores referentes à composição dos ovos provenientes de codornas japonesas com diferentes idades, e armazenados por 21 dias sob temperatura refrigerada encontram-se na Tabela 4.

Para PAL verificou-se interação entre idade da codorna e período de armazenamento, de forma que, ao longo do tempo de armazenamento o percentual de albúmen dos ovos de codornas com 40 semanas de idade reduziu de forma mais intensa em comparação aos produzidos pelas codornas mais jovens (Figura 16). Esse resultado, provavelmente, esteja ligado à perda de água do albúmen que se acentua devido à má qualidade de casca de ovos produzidos por aves de idade mais avançada.

Tabela 4: Porcentagens de albúmen (PAL), gema (PG) e casca (PC), sólidos totais (\%) de albúmen (SA) e gema (SG) de ovos de codornas japonesas armazenados sob temperatura refrigerada em função da idade (ID) e do período de armazenamento (PA)

\begin{tabular}{|c|c|c|c|c|c|}
\hline ID (semanas) & & & Porcentagens & Sólidos totais $(\%)$ & \\
\hline & PAL & PG & $\mathrm{PC}$ & AS & SG \\
\hline 13 & 50,36 & 34,19 & 15,45 & $9,02 \mathrm{a}$ & 18,76 \\
\hline 40 & 49,00 & 37,20 & 15,76 & $8,69 b$ & 19,61 \\
\hline \multicolumn{6}{|l|}{ PA (dias) } \\
\hline 0 & 54,68 & 31,55 & 13,76 & 8,98 & 20,18 \\
\hline 7 & 50,28 & 34,37 & 15,34 & 8,93 & 19,49 \\
\hline 14 & 48,63 & 36,08 & 15,29 & 8,99 & 19,86 \\
\hline 21 & 45,12 & 40,76 & 18,03 & 8,51 & 17,21 \\
\hline \multicolumn{6}{|c|}{ Valores de $\mathrm{P}$} \\
\hline ID & 0,055 & $<0,01$ & $>0,05$ & 0,041 & 0,141 \\
\hline PA & $<0,01$ & $<0,01$ & $<0,01$ & 0,115 & $<0,01$ \\
\hline ID $\times$ PA & 0,030 & $<0,01$ & 0,126 & 0,286 & 0,318 \\
\hline
\end{tabular}

Na coluna, médias seguidas de letras diferentes diferem entre si pelo $\mathrm{F}(\mathrm{P}<0,05)$

Figura 16: Desdobramento da interação entre a idade da poedeira e período de armazenamento (21 dias) para a variável porcentagem de albúmen sob temperatura refrigerada

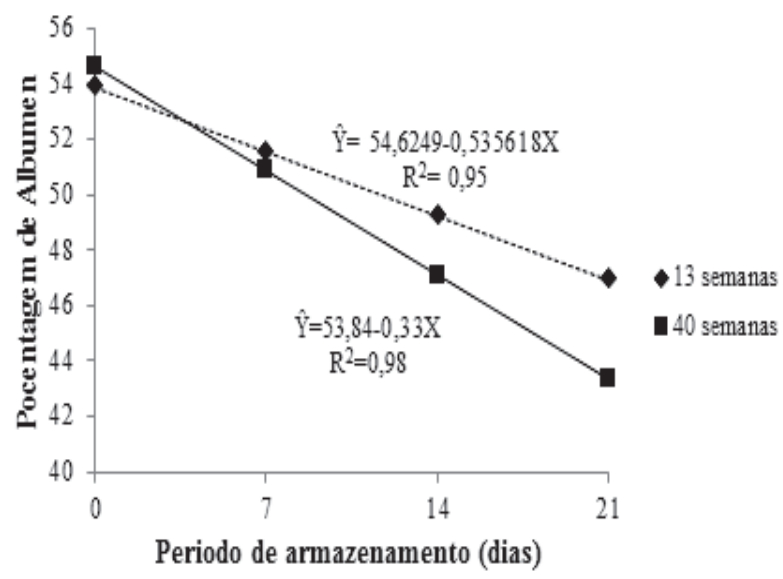

Houve interação entre a idade da poedeira e o período de armazenamento para PG (Figura 17), em que os ovos de codornas mais velhas apresentaram aumento quadrático e os ovos das aves mais jovens demonstraram aumento linear com avanço do período de estocagem.

Em estudos com poedeiras com 26 semanas, Garcia et al. (2010) observaram efeito linear para a PG dos ovos com o aumento do tempo de armazenamento tanto os ovos que foram estocados em ambiente refrigerado com os mantidos em temperatura ambiente.

Ao analisar ovos estocados em diferentes temperaturas (ambiente e refrigerado), armazenados por 21 dias, Freitas et al. (2011) não observaram efeito significativo da PG em relação ao peso do ovo. 
Figura 17: Desdobramento da interação entre a idade da poedeira e período de armazenamento (21 dias) para a variável porcentagem de gema sob temperatura refrigerada

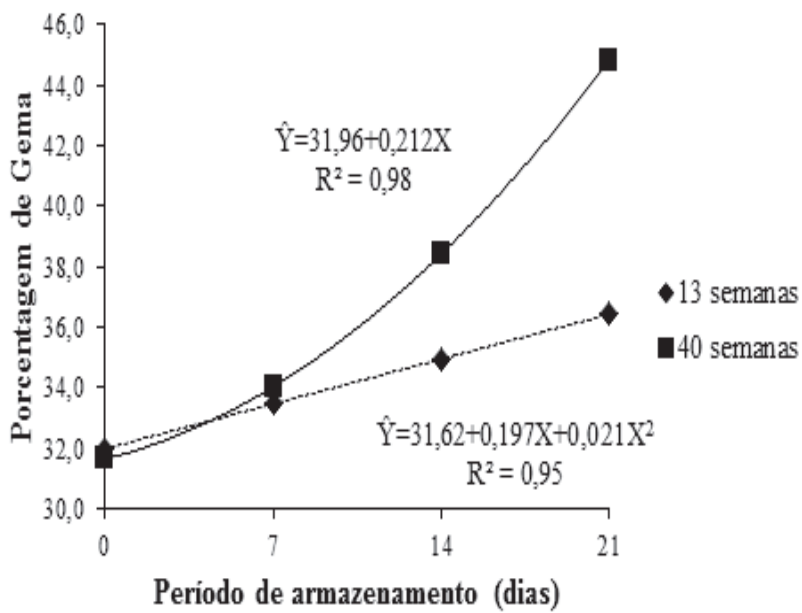

Não houve efeito da idade da codorna para PC dos ovos armazenados sob refrigeração, no entanto, observou-se aumento linear crescente sobre essa variável com o avanço do tempo de estocagem (Figura 18).

Figura 18: Porcentagem de casca de ovos provenientes de codornas japonesas, armazenados por 21 dias sob temperatura refrigerada

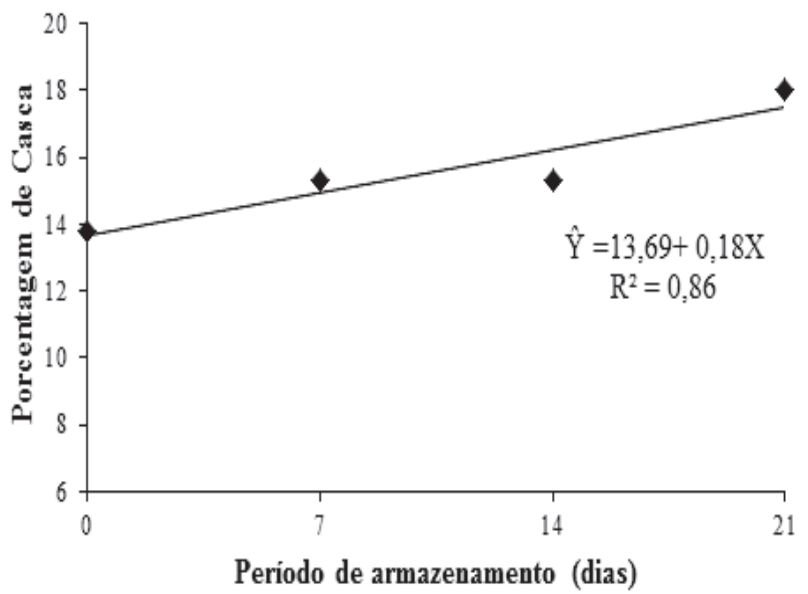

Verificou-se efeito isolado da idade para a variável SA, resultado que pode ser explicado por poedeiras mais velhas produzem ovos maiores e ao mesmo tempo possuem deficiência maior em depositar nutrientes tanto no albúmen como na gema. Por outro lado, os valores referentes aos SG dos ovos apresentaram efeito linear decrescente (Figura 19) quando mantidos sob temperatura refrigerada com o avanço do período de armazenamento.

Corroborando com os resultados apresentados neste trabalho, Garcia et al. (2010) demostraram que a porcentagem de sólidos totais de ovos de galinha armazenados em temperatura refrigerada, diminuíram linearmente ao longo do período de estocagem.
Figura 19: Sólidos totais da gema (\%) de ovos provenientes de codornas japonesas, armazenados por 21 dias sob temperatura refrigerada

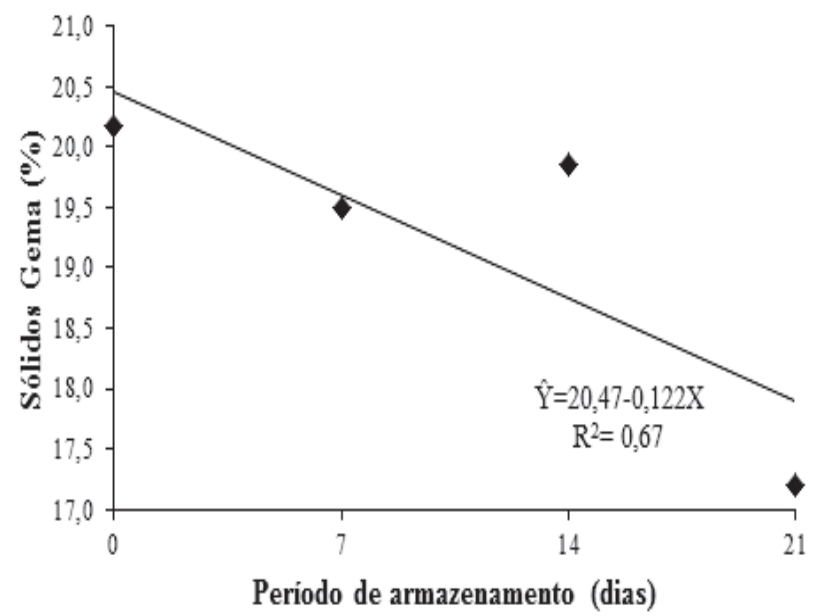

\section{Conclusão}

Os ovos produzidos por codornas mais velhas são mais susceptíveis a perda de qualidade interna. Quando armazenados sob temperatura ambiente os ovos de codornas apresentam perdas acentuadas de qualidade interna durante a estocagem por até 21 dias, independente da idade das aves. A refrigeração apresenta-se como uma alternativa para prolongar a qualidade interna dos ovos de codornas.

\section{Referências}

ANDRADE, E. L. et al. Valor de ph e cor da gema de ovos de galinhas poedeiras armazenados em diferentes métodos e períodos. In: CONGRESSO BRASILEIRO DE ZOOTECNIA, 2009, Águas de Lindóia Anais... São Paulo, 2009. p. 39.

BARBOSA, N. A. A. et al. Qualidade de ovos comerciais provenientes de poedeiras comerciais armazenados sob diferentes tempos e condições de ambiente. ARS Veterinária, v. 24, p. 127-133, 2008.

\section{FERREIRA, J. I. Qualidade interna e externa de} ovos orgânicos produzidos por aves da linhagem Isa Brown ao longo de um período de postura. 2013. 64 f. Dissertação (Mestrado em Ciências Veterinárias) Universidade Federal do Rio Grande do Sul, Porto Alegre, 2013.

FIGUEIREDO, T. C. Influencia das condições e do período de armazenamento nas características físicoquímicas, microbiológicas e nos níveis de aminas bioativas em ovos para exportação. 2012. $113 \mathrm{f}$. Tese (Doutorado em Ciência Animal) - Universidade Federal de Minas Gerais, Belo Horizonte, 2012.

FREITAS, L. W. et al. Aspectos qualitativos de ovos comerciais submetidos a diferentes condições de armazenamento. Revista Agrarian, v. 4, p. 66-72, 2011. 
FUJIKURA, W. S. Situação e perspectivas da coturnicultura no Brasil. In: SIMPÓSIO INTERNACIONAL DE COTURNICULTURA, 01, 2002, Lavras. Anais... Lavras: UFLA, 2002. p. 01-10.

GARCIA, E. R. M. et al. Qualidade de ovos de poedeiras semipesadas armazenados em diferentes temperaturas e períodos de estocagem. Revista Brasileira de Saúde Produção Animal, v. 11, p. 505-518, 2010.

JONES, D. R. et al. Effects of cryogenic cooling of shell eggs on egg quality. Poultry Science, v. 81, p. 727-733, 2002.

MARINHO, A. L. Qualidade interna e externa de ovos de codornas japonesas armazenados em diferentes temperaturas e períodos de estocagem. 2011. $81 \mathrm{f}$. Dissertação (Mestrado em Zootecnia) - Universidade Federal de Alagoas, Maceió, 2011.

MORAES, V. M. B.; ARIKI, J. Importância da nutrição na criação de codornas e qualidades nutricionais do ovo e da carne de codorna. In: SECRETARIA DE AGRICULTURA E ABASTECIMENTO DE MOGI DAS CRUZES. 2000, Mogi das Cruzes. Anais... Mogi das Cruzes, 2000. p. 114120 .

MORENG, R. E.; AVENS, J. S. Ciência e produção de aves. São Paulo: Roca, 1990. 394 p.

MOURA, A. M. A. et al. Efeito da temperatura de estocagem e do tipo de embalagem sobre a qualidade interna de ovos de codornas japonesas (Coturnix japonica). Ciência e Agrotecnologia, v. 32, p. 578-583, 2008.

NESHEIM, M. C.; AUSTIC, R. E.; CARD, L. E. Poultry production. 12. ed. Philadelphia: Lea \& Febiger, 1979. 339 p.

OLIVEIRA, G. E. Influência da temperatura de armazenamento nas características físico-químicas e nos teores de aminas bioativas em ovos. 2006. 79 f. Dissertação (Mestrado em Ciências dos Alimentos) Universidade Federal de Minas Gerais, Belo Horizonte, 2006.

PASTORE, S. M.; OLIVEIRA, W. P.; MUNIZ, J. C. L. Panorama da coturnicultura no Brasil. Revista Nutritime, v. 9, 2012.

ROCHA, J. S. R. et al. Efeito da classificação dos ovos sobre o rendimento de incubação e os pesos do pinto e do saco vitelino. Arquivo Brasileiro de Medicina Veterinária e Zootecnia, v. 60, p. 979-986, 2008.

SANTOS, M. S. V. et al. Efeito da temperatura e estocagem em ovos. Ciência e Tecnologia de Alimentos, v. 29, p. 513$517,2009$.

SCATOLINI-SILVA, A. M. et al. Qualidade física de ovos armazenados em diferentes condições de embalagens sob temperatura ambiente. Archivos de Zootecnia, v. 62, p. 247-254, 2013.

SEIBEL, N. F. et al. Influencia da temperatura de estocagem na qualidade interna de ovos de codornas alimentadas com dietas contendo diferentes níveis de silagem de pescado. Brazilian Journal of Food Technology, v. 8, p. 35-42, 2005.

SGARBIERI, V. C. Proteínas em alimentos proteicos: propriedades, degradações, modificações. São Paulo: Varela, 1996.517 p.

SOUSA, D. C. T. Influência da temperatura de armazenamento e da idade da galinha poedeira na qualidade de ovos produzidos em boa vista- RR. Universidade Federal de Roraima, Boa Vista, 2013.

SOUZA, H. B. et al. Influência de diferentes tipos de embalagens e tratamentos com óleo de mineral sobre a qualidade de ovos de consumo. In: CONGRESSO BRASILEIRO DE CIÊNCIA E TECNOLOGIA DE ALIMENTOS, 14., 1998, Rio de Janeiro. Anais... Rio de Janeiro: CBCTA, 1998. p. 592-600.

VIDAL, T. F. Qualidade, composição e estabilidade dos ovos de poedeiras alimentadas com farelo de castanha de caju. 2009. 65 f. Dissertação (Mestrado em Ciências e Tecnologias de Alimentos) - Universidade Federal do Ceará, Fortaleza, 2009.
Recebido em: 20.11.2015

Aceito em: 28.12.2015 